\title{
Flight initiation and flight activity in Prostephanus truncatus (Coleoptera: Bostrichidae)
}

\author{
D. Scholz ${ }^{1,2^{*}}$, C. Borgemeister ${ }^{1,2}$, R.H. Markham ${ }^{1}$ \\ and H.M. Poehling ${ }^{2}$ \\ ${ }^{1}$ International Institute of Tropical Agriculture, Plant Health Management \\ Division, 08 BP 0932, Tri Postal, Cotonou, Republic of Benin, West Africa: \\ ${ }^{2}$ Institut für Pflanzenkrankheiten und Pflanzenschutz, Universität \\ Hannover, Herrenhäuser Str. 2, 30419 Hannover, Germany
}

\begin{abstract}
In an outdoor experimental set-up, the number of Prostephanus truncatus (Horn) flying from maize cobs was recorded over 38 observation weeks. Flight activity in the field was recorded for 50 weeks with three pheromone traps, each placed at c. $100-300 \mathrm{~m}$ from the first experimental set-up. Multiple regression analyses revealed that both flight initiation and flight activity were partly influenced by mean temperatures, but were not directly related. Flight initiation was mainly dependent on population density. An additional experiment showed that sex ratios among pheromone trap catches were not correlated with the number of beetles caught; sex ratios were female-biased throughout the year. Seasonal fluctuations in flight activity recorded with pheromone traps are mainly dependent on changes in the number and sizes of beetle populations in a given area, as well as on breeding site availability and suitability.
\end{abstract}

\section{Introduction}

The larger grain borer, Prostephanus truncatus (Horn) (Coleoptera: Bostrichidae), originated from Central America and Mexico, and was accidentally introduced into East and West Africa in the late 1970s and early 1980s, respectively (Dunstan \& Magazini, 1981; Krall, 1984). In many of the outbreak countries, the beetle has become the most serious pest of farm-stored maize and dried cassava (e.g. McFarlane, 1988; Markham et al., 1991). Since P. truncatus belongs to a family of wood-boring beetles (Freude et al., 1969) and has been found to reproduce in certain woody plants in laboratory experiments (Nang'ayo, 1996) and in the field (RamírezMartínez et al., 1994; Borgemeister et al., 1998a), the pest may only be facultatively associated with these stored commodities.

On a suitable food source, male $P$. truncatus produce an aggregation pheromone (Smith et al., 1996) which attracts male and female conspecifics (e.g. Obeng-Ofori \& Coaker,

*Fax: 495117623015

E-mail: scholz@mbox.ipp.uni-hannover.de
1990). The two main components of the pheromone have been identified (Cork et al., 1991), synthesized, and used to determine the beetle's spread and flight activity (Richter \& Biliwa, 1991; Borgemeister et al., 1997). Studies in Kenya (Giles et al., 1995; Nang'ayo, 1996), Benin (Borgemeister et al., 1997) and Mexico (Tigar et al., 1994) showed strong seasonal fluctuations in the numbers of $P$. truncatus caught with pheromone-baited traps. Variations in trapping rates were partly related to meteorological parameters. In East Africa, peaks in flight activity coincided with the short rainy season (Nang'ayo, 1996); in Mexico, Tigar et al. (1994) found an association with rainfall in the drier regions but not for humid areas; and Borgemeister et al. (1997) reported mean temperature as the only meteorological parameter correlated with pheromone trap catches in Benin. According to Johnson (1969), flight activity is dependent on the number and size of populations in an area, the proportions of them in flight, and, consequently, on flight initiation and the time the beetles spend flying. Therefore, we were interested in determining whether flight initiation was directly influenced by seasonal cues, or if the observed fluctuations in flight activity can be explained by the abundance of $P$. truncatus in an area and by 
factors affecting flight initiation indirectly, e.g. population density and breeding habitat degradation or destruction.

To separate direct seasonal influences on flight initiation from factors influencing flight activity, two experiments were conducted simultaneously. Flight initiation was determined in an outdoor experimental set-up with controlled population densities. Natural flight activity in the area surrounding the experimental set-up was recorded with pheromone traps in a second experiment.

During periods of high flight activity, female-biased sex ratios have been observed among $P$. truncatus caught with pheromone traps (Scholz et al., 1997). To investigate if high flight activity may, at least in part, be explained by a higher proportion of females dispersing, the number and sex ratios of $P$. truncatus caught with pheromone traps were recorded over one year in a third experiment.

\section{Materials and methods}

\section{Insects}

Initial laboratory cultures of $P$. truncatus were set up with individuals collected in the Mono District of south-western Benin in 1992. Beetles, collected in the same region, were routinely added to the cultures, every four to six months. The insects were reared on maize grains ( $350 \mathrm{~g}$; cv. TZSR-W) in $1000 \mathrm{ml}$ glass jars covered with brass gauze at $30 \pm 1^{\circ} \mathrm{C}$ and $75 \pm 5 \%$ relative humidity (r.h.) under a L12:D12 photoperiod. The maize was infested with 200 unsexed adult $P$. truncatus, all of which were removed after two weeks to obtain a synchronized F1.

\section{Experiment 1: flight initiation}

Maize cobs (weight: 75-85 g; cv. TZSR-W) were frozen at $-15^{\circ} \mathrm{C}$ for two weeks in order to disinfest the maize from hidden insect infestations, and then reconditioned at $30 \pm 1^{\circ} \mathrm{C}$ and $75 \pm 5 \%$ r.h. for at least 14 days. A hole $(c .0 .8 \mathrm{~cm}$ wide and $5 \mathrm{~cm}$ deep) was drilled in the base of the cobs and eight cobs were each infested weekly with five male and five female $P$. truncatus. The infested cobs were stored singly in $1000 \mathrm{ml}$ glass jars with a rough interior (made with sand and sodium silicate) in an open field laboratory $\left(24-35^{\circ} \mathrm{C}\right.$, $50-100 \%$ r.h.). The first adults of the progeny started to emerge after four weeks and flight initiation started a further week later. Thus, the infested cobs were transferred to the experimental units (fig. 1) after five weeks.

The experimental units were set up under a roofed shelter $(3 \times 3 \mathrm{~m}, 2.5 \mathrm{~m}$ high), which had been constructed on the campus of the International Institute of Tropical Agriculture (IITA) in Abomey-Calavi, Republic of Benin. The sides of the shelter were covered with shade cloth, to provide protection against direct sunlight. Each experimental unit (fig. 1) consisted of a light-permeable, polyethylene bucket, which was inverted and fitted on top of a funnel. Two 'windows' $(10 \times$ $10 \mathrm{~cm}$ ) were cut into the walls of the polyethylene bucket and screened with brass gauze. A removable collection container was attached at the exit pipe of the funnel and two metal bars ( $2 \mathrm{~mm}$ diameter) were inserted across the top of the funnel. A construction resembling a candle holder was fixed on the metal bars inside each experimental unit. The holder was made of a cut plastic cup and a screw; the floor of the cup was covered with a mixture of sand and sodium silicate, and the infested maize cobs (including any flour

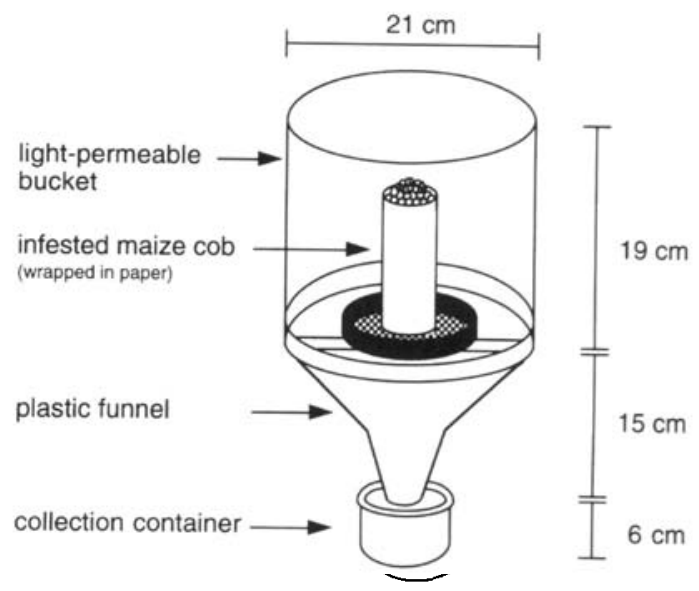

Fig. 1. Experimental unit. The light-permeable, but non-transparent, bucket is presented transparent and the screened windows are omitted.

produced) were wrapped in a paper towel and placed on the holder. This design enabled the beetles which fell off the cob to crawl back onto it, but prevented them from climbing the smooth rim of the holder. Beetles flying off the cobs hit the walls and dropped into the collection container, which they could not leave.

Beetles which had flown off the maize cobs, and had gathered in the collection containers ('flyers'), were collected and counted three times per week for the following 21 days. After the final collection on day 21, the cobs were removed from the experimental units and all $P$. truncatus still left on the cobs were counted. Since there were 24 experimental units and eight cobs were set up weekly to replace the removed cobs, in every observation week there were cobs in the first, the second and the third week after set-up ('flight weeks'), except for the two weeks at the beginning and at the end of the experiment. The experiment was run from February to November 1996 over a total of 38 observation weeks.

\section{Experiment 2: flight activity}

Three Delta sticky traps (Pherocon II trap, Trécé, Inc., USA) baited with polyethylene vials containing the synthetic aggregation pheromone of $P$. truncatus (1 $\mathrm{mg} 1$-methylethyl (E)-2-methyl-2-heptenoate ('Trunc-call1', T1) and $1 \mathrm{mg} 1$ methylethyl (E,E)-2-4-dimethyl-2,4 heptadienoate ('Trunccall2, T2); AgriSense-BCS Ltd., Pontypridd, UK) were distributed within the IITA Benin campus, $c .100-300 \mathrm{~m}$ from the experimental set-up of Experiment 1. Distances between traps were $c .300 \mathrm{~m}$. The traps were collected for insect counts and replaced by new traps with fresh pheromone vials weekly (on the same day the cobs were exchanged in Experiment 1). The experiment was run over 50 weeks from December 1995 to November 1996.

\section{Determination of temperature and relative humidity}

Weather data (maximum and minimum daily temperatures (Tmax, Tmin), maximum and minimum relative 
humidity (r.h.max, r.h.min) and daily rainfall) were obtained from the IITA Benin weather station, situated c. $400 \mathrm{~m}$ from the experimental set-up of Experiment 1. Temperature and relative humidity were measured with a hygrothermograph (Oakton, spring-wound model). The weekly means for minimum and maximum temperatures and relative humidity were computed using the daily values. The weekly means for mean temperature and relative humidity were calculated using the daily means of the respective minimum and maximum values, i.e. (Tmin+Tmax)/2 and (r.h.min+r.h.max)/2 Total accumulated weekly rainfall was also computed. There was a strong correlation $(r>0.7)$ between the mean temperatures and minimum and maximum temperatures, as well as with minimum and mean relative humidity. Therefore, only the mean weekly temperatures and the mean weekly maximum relative humidity were selected as parameters describing temperature and relative humidity.

In order to verify if the temperature and relative humidity inside the experimental units and those measured at the IITA Benin weather station were similar, mean weekly temperatures and mean weekly maximum relative humidity measured at the two sites were compared. Two empty experimental units were supplied with one thermocouple and one relative humidity probe each, which were connected to a datalogger (Model 245, Wavetek Inc., San Diego, California, USA). Temperature and relative humidity were measured every $7 \mathrm{sec}$ and the $10 \mathrm{~min}$ means of the measurements were recorded with the datalogger-specific programme (Doric) on a personal computer for a total of 35 weeks. Weekly means (of both probes) were calculated from mean daily temperatures and from maximum daily relative humidity. As the measurements from the IITA weather station corresponded well with conditions recorded inside the experimental units (see Results), multiple regression procedures were performed with the data obtained from the IITA weather station.

\section{Experiment 3: trap catches and sex ratios}

The number and sex ratio of $P$. truncatus trapped with two pheromone traps (described in Experiment 2) were recorded from September 1994 to September 1995. The traps were part of a continuous monitoring programme in the Mono District in south-western Benin (Borgemeister et al., 1997) and were located c. $800 \mathrm{~m}$ apart. Traps were collected weekly, frozen at $-15^{\circ} \mathrm{C}$, and replaced by new traps with fresh pheromone vials. The sex of all intact beetles could be determined by squeezing the abdomen of the beetles to extrude the genitalia. If this number caught exceeded 100 beetles per trap, only a subsample of 100 beetles was sexed.

The amount of pheromone evaporating and the ratio of the components $\mathrm{T} 1$ and $\mathrm{T} 2$ have been reported to change over time (Dendy et al., 1991) and may, therefore, attract different sex ratios at the beginning and end of the trapping period. Beetles caught during the first few days of the trapping period were internally decomposed and could not be sexed. For this reason, we tested whether the intact beetles were a representative sample of all beetles trapped. Over a six week period the sex ratios of $P$. truncatus caught with two traps (c. $300 \mathrm{~m}$ apart), located near the IITA station, were determined. For one trap, the sex ratio was determined of all beetles trapped, collecting the beetles from the traps three times per week. The sex ratio among the beetles from the other trap was determined as described above, i.e. selecting non-decomposed beetles after one week. In order to avoid locational bias, the sampling methods were changed weekly between the two traps.

\section{Statistics}

Temperature and relative humidity recorded inside the experimental units and in the surroundings of the experimental set-up were compared using Wilcoxon signed ranks tests.

In Experiment 1, the relationship between flight initiation, weather parameters, experimental variables and $P$. truncatus caught with pheromone traps was investigated using a stepwise multiple regression analysis. All variables are listed in table 1 . In addition, multiple regressions using the same independent variables were performed separately for each flight week. Insect variables were log-transformed, i.e. $\log (n+1)$. To verify if the temperatures during the development periods influenced the final progeny densities, temperature sums (sum of mean weekly temperatures for the eight weeks between the initial cob infestation and removal of the cobs from the experimental units) were calculated for each progeny density. A correlation analysis was performed on progeny densities versus temperature sums. A second stepwise multiple regression analysis was used to determine the relationship between flight activity and weather variables (table 1).

The percentages of females recorded with the different sampling methods (in the preliminary experiment on sex

Table 1. Dependent and independent variables of the multiple regression models.

\begin{tabular}{ll}
\hline Dependent variable & Independent variable \\
\hline $\begin{array}{l}\text { No. }(\log (n+1)) \text { of } P \text {. truncatus flying } \\
\text { from maize cobs }\end{array}$ & $\begin{array}{l}\text { Progeny density, } \log (\mathrm{n}+1) \\
\text { Flight week } \\
\text { Cob weight } \\
\text { Mean weekly temperature } \\
\text { Mean maximum relative humidity } \\
\text { No. of } P, \text { truncatus caught with pheromone } \\
\text { traps, log }(\mathrm{n}+1)\end{array}$ \\
& $\begin{array}{l}\text { Mean weekly temperature } \\
\text { Mean maximum relative humidity } \\
\text { No. }(\log (\mathrm{n}+1)) \text { of } P . \text { truncatus caught } \\
\text { with pheromone traps }\end{array}$ \\
& Accumulated weekly rainfall \\
\hline
\end{tabular}


ratio determination) were compared using paired t-tests. To verify if there was an association between the sex ratios and the number of beetles caught with pheromone traps, a correlation analysis was performed on the total numbers of $P$. truncatus caught and the percentages of females. All statistical analyses were performed using SPSS for Windows (Norusis, 1993).

\section{Results}

Comparison of conditions inside the experimental units and in the surroundings of the experimental set-up

Mean temperatures measured inside the experimental units (mean $\left.=28.8^{\circ} \mathrm{C} ; \mathrm{SE}=0.2\right)$ were significantly $(P<0.05$ ) higher than mean temperatures measured at the IITA weather station (mean $=27.6^{\circ} \mathrm{C} ; \mathrm{SE}=0.2$ ). However, this difference was relatively small, and mainly caused by increased maximum temperatures around midday. There were no significant differences $(P>0.05)$ between the maximum relative humidity inside the experimental units (mean $=95.3 \%$; $\mathrm{SE}=0.4)$ and maximum relative humidity measured at the IITA weather station (mean $=94.8 \%$; SE $=0.4$ ). Hence, temperature and relative humidity conditions inside and outside the experimental units were essentially the same.

\section{Experiments 1 and 2}

Analysing factors which may have affected the number of beetles flying from maize cobs revealed that flight week, progeny density and mean weekly temperature contributed significantly to the proposed regression model (table 2; fig. 2). Including any of the other independent variables did not improve the model, which explained c. $70 \%$ of the variance. According to the standardized regression coefficients, the contribution of the independent variables to the model can be summarized as: flight week $>$ progeny density $>$ temperature (table 2). Examination of the influence of progeny density and temperature separately for the three flight weeks showed that the contribution of the mean temperature to the regression decreased from flight week one to flight week three; conversely that of the progeny density increased from flight week one to flight week three (table 2; fig. 2).

There was no significant correlation between 'final progeny densities' and 'temperature sums during the development time' $(r=0.17 ; P>0.05)$

Investigating the factors which may have influenced the number of $P$. truncatus caught with pheromone traps, only the mean weekly temperature significantly contributed to the regression model (table 2; fig. 3). Approximately $30 \%$ of the variance could be explained by this variable.

\section{Experiment 3}

In preliminary trials, we recorded $76.5 \%(\mathrm{SE}=1.3$ $\mathrm{n}=1722$ ) females when all trapped beetles were sexed. When the sex was determined only for non-decomposed beetles or a sample of them (the standard method applied in the main experiment), the proportion of females averaged $78.2 \%(\mathrm{SE}=2.2 ; \mathrm{n}=573)$. As these means did not differ significantly (paired t-test, $P=0.62$ ), the applied standard sex determination method was considered appropriate to determine sex ratios among $P$. truncatus caught with pheromone.

Table 2. Multiple regression analyses for assessing (1) the effect of weather and experimental factors on the number of Prostephanus truncatus flying from maize cobs and (2) the effect of weather on the number of $P$. truncatus caught with pheromone traps. Data (1): February to November 1996; data (2): December 1995 to November 1996. Documented variables contributed significantly to the models $(P<0.05)$, except mean temperature in flight week $3 ; b$, standardized regression coefficient; $t$, $t$-statistics; $r^{2}$, coefficient of determination; $d f$, degrees of freedom; SE, standard error.

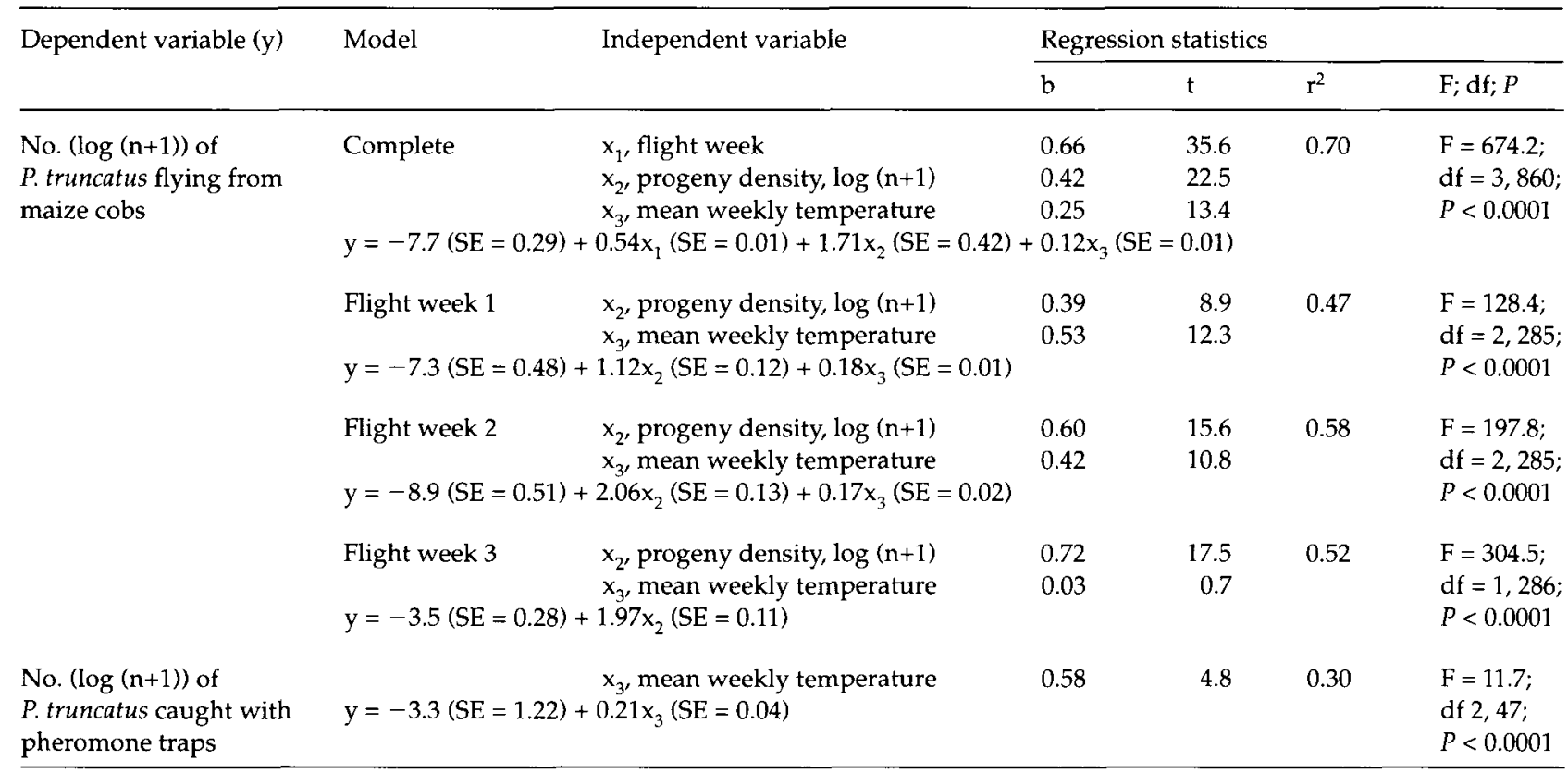




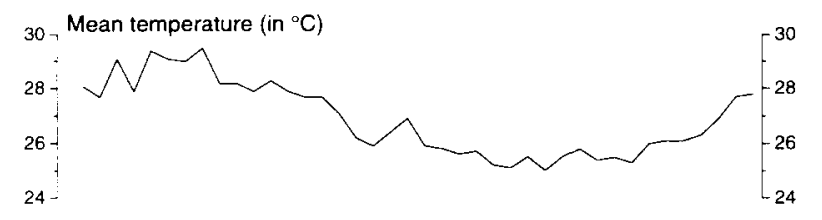

Final progeny density
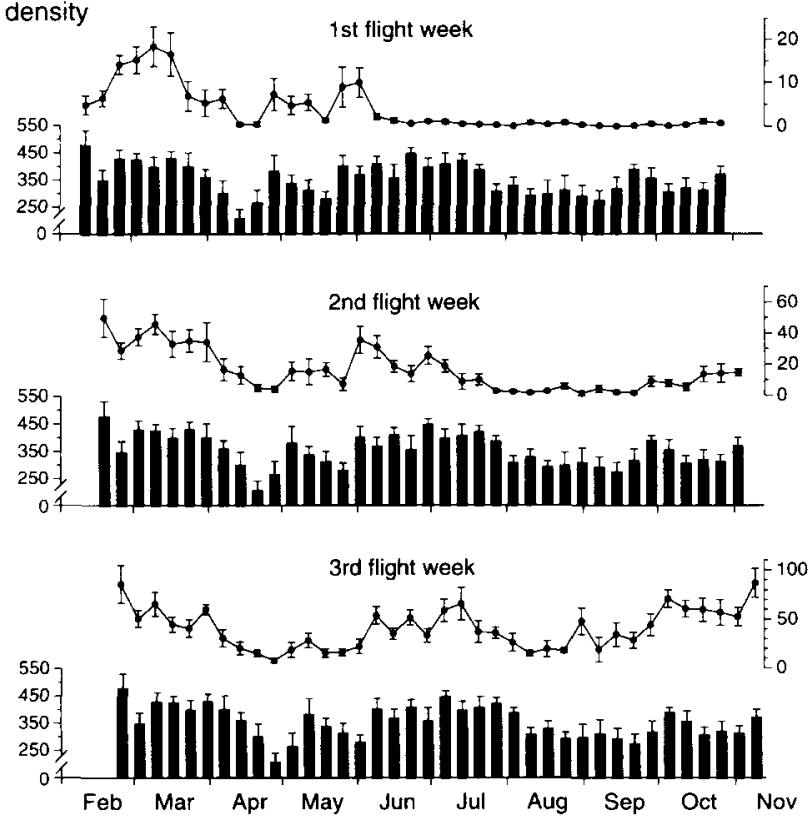

Fig. 2. Fluctuations of the number of Prostephanus truncatus which flew from a cob in relation to final progeny densities and mean temperatures (February-November 1996). The same mean progeny density corresponds with flyers of the first, the second and the third flight week. Error bars represent $1 \mathrm{SE}$.

Figure 4 presents the fluctuations of trap catches and sex ratios during the 54 weeks of trapping in the Mono District. Few beetles were caught from September to December, while peaks in flight activity were recorded from March to June. The proportion of females caught during the whole experimental period averaged $72 \%$ at both trapping locations (trap 1: $n=3253$, trap 2: $n=3714$ ). The correlation between the number of beetles and the percentage of females trapped was not significant (trap 1: $r=0.03, P>0.05$; trap 2: $\mathrm{r}=0.04, P>0.05$ ).

\section{Discussion}

During a time of the year when flight activity was high, sex ratios were female-biased among $P$. truncatus caught with pheromone traps (Scholz et al., 1997), while sex ratios among non-dispersing P. truncatus in maize laboratory cultures (Shires, 1979; Scholz, 1997) and in maize stores (Scholz, 1997) have been found to be $c .1: 1$. However, as sex ratios recorded for weekly catches with pheromone traps were always female-biased and were not correlated with the numbers of $P$. truncatus caught, peaks in flight activity were not caused by an increased proportion of females migrating. In
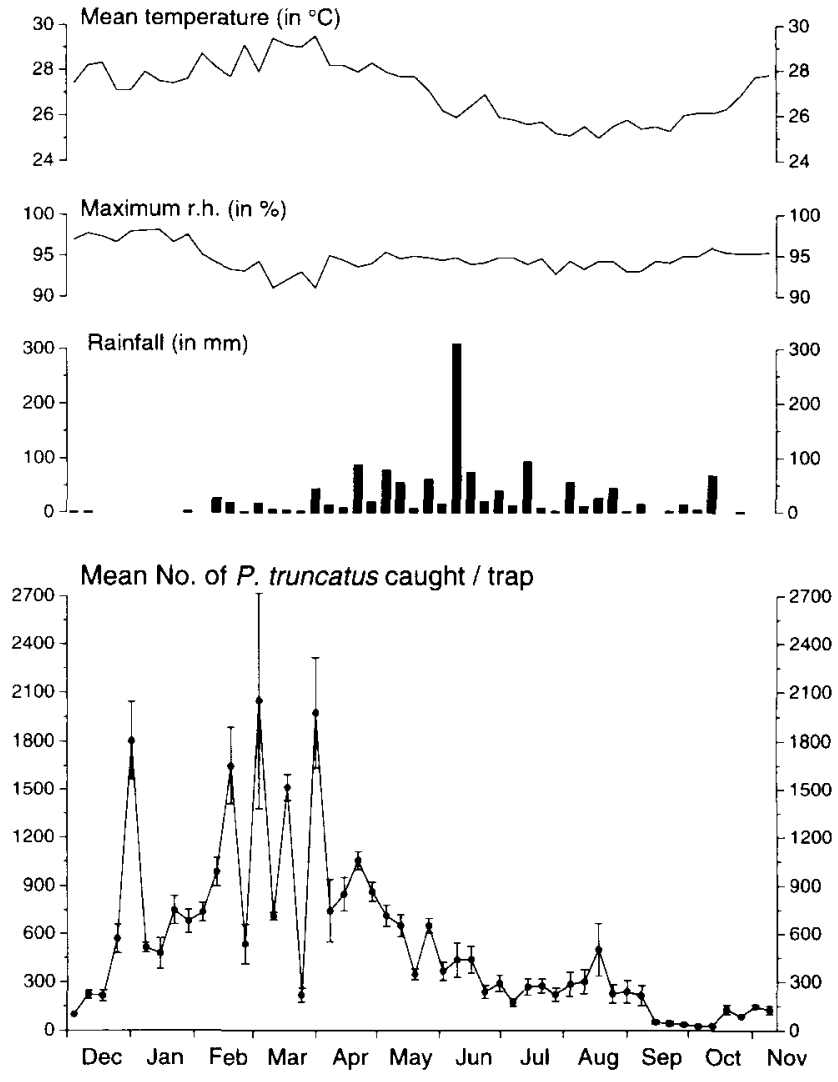

Fig. 3. Annual fluctuations of the number of Prostephanus truncatus caught with pheromone traps on the campus of the IITA station and corresponding weather data used in the multiple regression (December 1995 to November 1996). Error bars represent 1 SE.

contrast, trap catches of Pityogenes chalcographus Linnaeus (Coleoptera: Scolytidae) with the synthetic aggregation pheromone of the beetle were male-biased during high, and balanced, or female-biased, during low flight activity (Zumr, 1988).

As observed in a previous experiment (Scholz, 1997), flight initiation of $P$. truncatus was strongly influenced by the immediate population densities. Final progeny densities as well as flight week (with underlying rising progeny densities) were the major parameters affecting the number of beetles taking flight. Thus this experiment confirms that $P$. truncatus reacts to crowding and to the accompanying degradation of the food source with migration. In a food source analysis of migrating $P$. truncatus, Borgemeister $e t a l$. (1998b) found that during peak flight activity between January and March at the IITA station in Benin, the majority of the insects contained starch in their guts, indicating that the beetles had recently emigrated from nearby maize or cassava stores. This period of the year coincides with the end of the major storage period in southern Benin (Agbaka, 1996). Density dependent emigration has also been observed for other storage beetles (Ziegler, 1978; Barrer et al., 1993).

Multiple regression analyses revealed that from the 


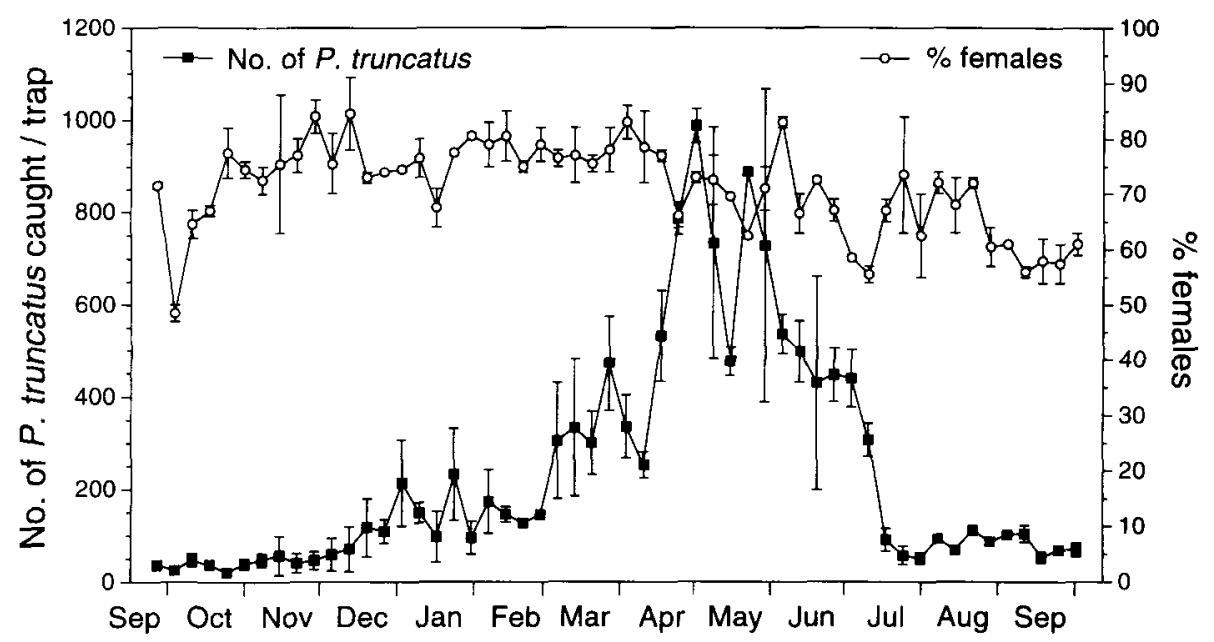

Fig. 4. Annual fluctuations of Prostephanus truncatus caught with pheromone traps in the Mono District and corresponding sex ratios. Means of two traps $( \pm 1 \mathrm{SE})$.

weather parameters considered for both $P$. truncatus caught with pheromone traps and beetles flying from the maize cobs, only mean temperature affected the number of beetles dispersing. The mean temperatures recorded in the experimental set-up were significantly higher than the ones obtained from the IITA weather station. However, this was only due to higher temperatures in the experimental set-up around noon. Since $P$. truncatus flies only at dusk and dawn (Tigar et al., 1993; Scholz, 1997), we do not think that these temperature differences had an effect on the numbers of beetles flying from the maize cobs. In addition, the temperature sums during the development period did not influence the size of the final progeny densities, and indirectly also not the number of flyers, it can be assumed that higher temperatures promoted dispersal, possibly due to the increased activity of the insects (Johnson, 1969). During a three-year observation period near the IITA Benin station, Borgemeister et al. (1997) found mean temperature to be the only meteorological variable to influence the fluctuations in flight activity, recorded with pheromone-baited traps. It can be assumed that trap catches in our experiment were not affected by increased pheromone release rates under warmer conditions, as (i) higher mean temperatures also increased migration in our experiment on flight initiation, and (ii) accompanying trap catches of the predator Teretriosoma nigrescens Lewis (Coleoptera: Histeridae) in the experiment of Borgemeister $e t$ al. (1997) were not influenced by temperature. Tigar et al. (1994) reported peaks in flight activity to be positively related to rainfall in the drier but not in the humid regions of Mexico, and Nang'ayo (1996) observed an increase in flight activity during the minor, but not during the major rainy season in Kenya. However, no association between flight activity and rainfall was observed in the present study.

The variance of both dependent variables (beetles flying off the cobs and beetles caught with pheromone traps) could partly be explained by variation in temperature. However, the flight activity recorded in the field was not related to dispersal as observed in Experiment 1. Seasonal cues, which have been suggested to initiate dispersal in other insect species (Johnson, 1969; Dingle, 1972, 1985; Mitchell et al., 1972; Forsse \& Solbreck, 1985), had no apparent effect on flight initiation of P. truncatus. Photoperiod or temperature changes may be adequate environmental cues signalling future conditions, e.g. availability of host plants; in tropical regions, however, these parameters change little and insects may rather respond directly to the suitability of the immediate habitat (Dingle, 1972). Dispersing P. truncatus may have emigrated from maize or cassava stores or from woody plants, the natural habitat (Ramírez-Martínez et al., 1994 Borgemeister et al., 1998a, b), and different factors may influence emigration from these patches. The flight activity pattern as observed between December 1995 and November 1996 at the IITA station (fig. 2) could well be explained in relation to storage practices. Maize stores in the area were established in August/September and subsequently P. truncatus populations increased within the stores (Borgemeister et al., 1997). Peaks in flight activity could, therefore, be attributed to increasing population densities in stores. In addition farmers start to empty stores from approximately November onwards until April/May, with the majority of stores being emptied between December and February (Agbaka, 1996), thereby disturbing the breeding populations and eliciting dispersal. Between June and September flight activity remained at a moderate level and varied little, with beetles possibly emigrating from store residues and patches in the natural habitat. When maize cobs matured in the fields and thereby developed suitable breeding conditions for $P$. truncatus (Giles et al., 1995), trap catches decreased to low levels, possibly due to the abundant alternative pheromone sources (male $P$. truncatus on maize)

The area around the IITA station and the Mono District in south-western Benin are both maize-growing regions with similar climatic conditions and storage practices; however, there is less natural vegetation in the peri-urban environment around the IITA station than in the Mono District. The annual flight activity patterns differ between these zones (cf. fig. 2 and fig. 4). In both regions, flight activity was lowest between September and December, and increased thereafter, 
but the major peaks in the Mono District occurred later than around the IITA station, namely at the end of the major dry season and the beginning of the main rainy season. Hence, flight activity in the Mono District must have been partly affected by factors different from those influencing migration near the IITA station. In their analyses of seasonality of flight activity and the origin of migrating P. truncatus, Borgemeister et al. (1997 and 1998b) concluded, that mainly the availability of host plants and not so much weather factors were responsible for peaks in flight activity. Strong seasonal fluctuations in the flight activity of $P$. truncatus were also observed in bushland areas of Kenya and Benin (Giles et al., 1995; Nang'ayo, 1996; Borgemeister et al., 1998a). Note that seasonality not only includes the annual pattern of metereological factors, but also the crop production, the storage cycle of the commodities, and seasonal changes in the vegetation. In the natural forest habitat of $P$. truncatus, migration may be dependent on the degradation and availability of natural host plants in time and space. For instance, heavy rains may destroy breeding sites or reduced habitat suitability [e.g. due to mould growth in moist substrates, which increases larval mortality (Bell \& Watters, 1982)], thereby initiating migration and, at the same time, reducing progeny production which in turn may lead to the dramatic drop in flight activity after the major dispersal period.

We conclude that dispersal from stored commodities is mainly dependent on population density and accompanying food degradation. Similar effects can be assumed to act in the beetle's natural habitat, although due to the presumably inferior nutritional value of these natural, woody host plants, migration may already occur at much lower population densities and possibly also at higher rates. Weather factors, as suggested by Tigar et al. (1994), Giles et al. (1995) and Borgemeister et al. (1997), may affect flight initiation (and thereby flight activity) only partly or indirectly. Higher mean temperatures may increase the beetle's general activity, and habitat suitability may be reduced by humid conditions thereby inducing dispersal. In addition, changes in temperature and rainfall may coincide with population increase and habitat availability. Variations in flight activity cannot simply be interpreted by considering the suitability of conditions for reproduction (such as preferred temperature and relative humidity), but must take into account local specifics in storage practices and changes in the availability of alternative host plants. Observed low flight activity may reflect a momentary low abundance of the beetles in an area, but may also result from an increased number of suitable food sources present.

\section{Acknowledgements}

We thank Mr S. Awande for assistance during the experiment, and Drs F. Schulthess, M. Raj, and L.E.N. Jackai for most helpful criticism of the manuscript. Special thanks to AgriSense-BCS Ltd., Pontypridd, UK, for providing the artificial pheromone. D. Scholz was initially supported by a research grant from the German Academic Exchange Service (DAAD) and was later financed by a scholarship from the Gottlieb Daimler- and Karl Benz-Foundation. The work was conducted within the framework of projects supported by the German Ministry for Economic Cooperation and Development (BMZ) and the Danish International Development Agency (DANIDA).

\section{References}

Agbaka, A. (1996) Etude biologique et possibilité de lutte integrée contre Prostephanus truncatus (Horn) (Coleoptera: Bostrichidae) ravageur des stocks de maïs dans les milieux paysans en République du Bénin. PhD thesis, xvi $+145 \mathrm{pp}$. Faculté des Sciences et Techniques de l'Université National de Côte d'Ivoire, Côte d'Ivoire.

Barrer, P.M., Starick, N.T., Morton, R. \& Wright, E.J. (1993) Factors influencing initiation of flight by Rhyzopertha dominica (F.) (Coleoptera: Bostrichidae). Journal of Stored Products Research 29, 1-5.

Bell, R.J. \& Watters, F.L. (1982) Environmental factors influencing the development and rate of increase of Prostephanus truncatus (Horn) (Coleoptera: Bostrichidae) on stored maize. Journal of Stored Products Research 18, 131-142.

Borgemeister, C., Meikle, W.G., Scholz, D., Adda, C., Degbey, P. \& Markham, R.H. (1997) Seasonal and weather factors influencing the annual flight cycle of Prostephanus truncatus (Coleoptera: Bostrichidae) and its predator Teretriosoma nigrescens (Coleoptera: Histeridae) in Benin. Bulletin of Entomological Research 87, 239-246.

Borgemeister, C., Goergen, G., Tchabi, A. Awande, S., Markham, R.H. \& Scholz, D. (1998a) Exploitation of a woody host plant and cerambycid associated volatiles as host finding cues by the larger grain borer, Prostephanus truncatus (Horn) (Coleoptera: Bostrichidae). Annals of the Entomological Society of America (in press).

Borgemeister, C., Tchabi, A. \& Scholz, D. (1998b) Trees or stores? The origin of migrating Prostephanus truncatus collected in different ecological habitats in southern Benin. Entomologia Experimentalis et Applicata 87, 285-294.

Cork, A., Hall, D.R., Hodges, R.J. \& Pickett, J.A. (1991) Identification of major component of male-produced aggregation pheromone of larger grain borer, Prostephanus truncatus (Horn) (Coleoptera: Bostrichidae). Journal of Chemical Ecology 17, 789-803.

Dendy, J., Dobie, P., Saidi, J.A., Smith, J. \& Uronu, B. (1991) Trials to assess the effectiveness of new synthetic pheromone mixtures for trapping Prostephanus truncatus (Horn) (Coleoptera: Bostrichidae) in maize stores. Journal of Stored Products Research 27, 69-74.

Dingle, H. (1972) Migration strategies of insects. Science 175, $1327-1335$.

Dingle, H. (1985) Migration. pp. 375-415 in Kerkut G.A. \& Gilbert L.I. (Eds) Comprehensive insect physiology, biochemistry, and pharmacology. Vol. 9: Behavior. New York, Pergamon Press.

Dunstan, W.R. \& Magazini, I.A. (1981) Outbreaks and new records. Tanzania. The larger grain borer on stored products. FAO Plant Protection Bulletin 29, 80-81.

Forsse, E. \& Solbreck, C. (1985) Migration in the bark beetle Ips typographus L.: duration, timing and height of flight. Journal of Applied Entomology 100, 47-57.

Freude, H., Harde, K.W. \& Lohse, A.G. (1969) Die Käfer Mitteleuropas. Band 8.367 pp. Krefeld (Germany), Goecke und Evers Verlag.

Giles, P., Hill, G., Nang'ayo, F., Farrell, G., Stabrawa, A. \& Wekesa, P. (1995) Entomological and socio-economic investigations for the development of integrated pest management strategies against Prostephanus truncatus. xxiv +273 pp. Kenya Agriculture Research Institute (KARI), Nairobi, Kenya and Natural Resources Institute (NRI), Chatham Maritime, UK.

Johnson, C.G. (1969) Migration and dispersal of insects by flight. $763 \mathrm{pp}$. London, Methuen and Co. Ltd. 
Krall, S. (1984) A new threat to farm-level maize storage in West Africa: Prostephanus truncatus (Horn) (Coleoptera; Bostrichidae). Tropical Stored Products Information 50, 26-31.

Markham, R.H., Wright, V.F. \& Ríos Ibarra, R.M. (1991) A selective review of research on Prostephanus truncatus (Col.: Bostrichidae) with an annotated and updated bibliography. Ceiba 32, 1-90.

McFarlane, J.A. (1988) Pest management strategies for Prostephanus truncatus (Horn) (Coleoptera; Bostrichidae) as a pest of stored maize grain: present status and prospects. Tropical Pest Management 34, 121-132.

Mitchell, E.B., Hardee, D.D., Cross, W.H., Huddleston, P.M. \& Mitchell, H.C. (1972) Influence of rainfall, sex ratio, and physiological condition of boll weevils on their response to pheromone traps. Environmental Entomology 1, 438-440.

Nang'ayo, F.L.O. (1996) Ecological studies on larger grain borer in savanna woodlands of Kenya. PhD thesis, 179 pp. Imperial College, London, UK.

Norusis, M.J. (1993) SPSS for Windows. Base system users's guide. Release 6.0. $828 \mathrm{pp}$. Chicago, SPSS Inc.

Obeng-Ofori, D. \& Coaker, T.H. (1990) Some factors affecting responses of four stored product beetles (Coleoptera: Tenebrionidae and Bostrichidae) to pheromones. Bulletin of Entomological Research 80, 433-441.

Ramírez-Martínez, M., de Alba-Avila, A. \& Ramírez-Zurbía, R. (1994) Discovery of the larger grain borer in a tropical deciduous forest in Mexico. Journal of Applied Entomology 118, 354-360.

Richter, J. \& Biliwa, A. (1991) Landesweite Erhebung mittels Pheromonfallen zur Verbreitung von Prostephanus truncatus (Horn) (Col., Bostrichidae) in Togo. Anzeiger für Schädlingskunde, Pflanzenschutz, Umweltschutz 64, 89-92.

Scholz, D. (1997) Dispersal and host-finding behaviour of Prostephanus truncatus (Horn) (Col.: Bostrichidae). PhD thesis, $146 \mathrm{pp}$. University of Hannover, Germany.
Scholz, D., Borgemeister, C., Meikle, W.G., Markham, R.H. \& Poehling, H.-M. (1997) Infestation of maize by Prostephanus truncatus initiated by male-produced pheromone. Entomologia Experimentalis et Applicata 83, 53-61.

Shires, S.W. (1979) Influence of temperature and humidity on survival, development period and adult sex ratio in Prostephanus truncatus (Horn) (Coleoptera, Bostrichidae). Journal of Stored Products Research 15, 5-10.

Smith, J.L., Cork, A., Hall, D.R. \& Hodges, R.J. (1996) Investigation of the effect of female larger grain borer, Prostephanus truncatus (Horn) (Coleoptera: Bostrichidae), and their residues on the production of the aggregation pheromone by males. Journal of Stored Products Research 32, $171-181$.

Tigar, B.J., Key, G.E., Flores-S., M.E. \& Vazquez-A., M. (1993) Flight periodicity of Prostephanus truncatus and longevity of attraction to synthetic pheromone. Entomologia Experimentalis et Applicata 66, 91-97.

Tigar, B.J., Osborne, P.E., Key, G.E., Flores-S., M.E. \& Vazquez-A., M. (1994) Distribution and abundance of Prostephanus truncatus (Coleoptera: Bostrichidae) and its predator Teretriosoma nigrescens (Coleoptera: Histeridae) in Mexico. Bulletin of Entomological Research 84, 555-565.

Ziegler, J.R. (1978) Dispersal and reproduction in Tribolium: the influence of initial density. Environmental Entomology 7 , 149-156.

Zumr, V. (1988) Effectiveness of the aggregation pheromone Chalcoprax against Pityogenes chalcographus. Lesnictvi 34, 489-498.
(Accepted 19 June 1998)

(C) CAB INTERNATIONAL, 1998 